\title{
COX2 in CNS neural cells mediates mechanical inflammatory pain hypersensitivity in mice
}

\author{
Daniel Vardeh, ${ }^{1}$ Dairong Wang, ${ }^{2}$ Michael Costigan, ${ }^{1}$ Michael Lazarus, ${ }^{3}$ Clifford B. Saper, ${ }^{3}$ \\ Clifford J. Woolf, ${ }^{1}$ Garret A. FitzGerald, ${ }^{2}$ and Tarek A. Samad ${ }^{1}$ \\ ${ }^{1}$ Neural Plasticity Research Group, Department of Anesthesia and Critical Care, Massachusetts General Hospital, Harvard Medical School, \\ Boston, Massachusetts, USA. 2Institute for Translational Medicine and Therapeutics and Department of Pharmacology, University of Pennsylvania, Philadelphia, \\ Pennsylvania, USA. ${ }^{3}$ Department of Neurology and Program in Neuroscience, Beth Israel Deaconess Medical Center, \\ Harvard Medical School, Boston, Massachusetts, USA.
}

\begin{abstract}
A cardinal feature of peripheral inflammation is pain. The most common way of managing inflammatory pain is to use nonsteroidal antiinflammatory agents (NSAIDs) that reduce prostanoid production, for example, selective inhibitors of COX2. Prostaglandins produced after induction of COX2 in immune cells in inflamed tissue contribute both to the inflammation itself and to pain hypersensitivity, acting on peripheral terminals of nociceptors. COX2 is also induced after peripheral inflammation in neurons in the CNS, where it aids in developing a central component of inflammatory pain hypersensitivity by increasing neuronal excitation and reducing inhibition. We engineered mice with conditional deletion of Cox 2 in neurons and glial cells to determine the relative contribution of peripheral and central COX2 to inflammatory pain hypersensitivity. In these mice, basal nociceptive pain was unchanged, as was the extent of peripheral inflammation, inflammatory thermal pain hypersensitivity, and fever induced by lipopolysaccharide. By contrast, peripheral inflammation-induced COX2 expression in the spinal cord was reduced, and mechanical hypersensitivity after both peripheral soft tissue and periarticular inflammation was abolished. Mechanical pain is a major symptom of most inflammatory conditions, such as postoperative pain and arthritis, and induction of COX2 in neural cells in the CNS seems to contribute to this.
\end{abstract}

\section{Introduction}

COXs catalyze the first reactions in $\mathrm{PG}$ synthesis to form $\mathrm{PGH}_{2}$. Tissue-specific isomerases ( $\mathrm{PG}$ synthases) convert $\mathrm{PGH}_{2}$ into 4 different PG isoforms $(1,2)$, which exert their biological actions via specific $\mathrm{G}$ protein-coupled receptors (3-6). COX2 is the dominant, but not exclusive, source of PGs induced by inflammatory stimuli $(7,8)$, whereas COX1 is the predominant source of prostanoids that mediate "housekeeping" functions (9). COX2 is also constitutively expressed in the CNS (10).

Inflammation is accompanied by spontaneous pain and hypersensitivity to mechanical and thermal stimuli. Marked increases in COX2 expression occur locally at the site of inflammation (11) and in neurons, glia, and endothelial cells in the spinal cord and brain $(11,12)$. Release of $\mathrm{PGE}_{2}$ at the site of peripheral inflammation contributes to pain hypersensitivity by reducing the threshold and increasing the excitability of peripheral terminals of nociceptor sensory fibers. This results from an E prostanoid (EP) receptor-mediated activation of intracellular kinases in the nociceptor terminal that phosphorylate the noxious heat transducer TRPV1 $(13,14)$ and the Nav1.8 voltage-gated sodium channel $(15-17)$ to produce peripheral sensitization, a change in thermal sensitivity confined to the area of inflammation. Increases in $\mathrm{PGE}_{2}$ in the $\mathrm{CNS}$ after peripheral inflammation mediate a widespread increase

Authorship note: Daniel Vardeh and Dairong Wang contributed equally to this work.

Conflict of interest: The authors have declared that no conflict of interest exists. Nonstandard abbreviations used: EP, E prostanoid.

Citation for this article: J. Clin. Invest. 119:287-294 (2009). doi:10.1172/JCI37098. in mechanical pain sensitivity due to synaptic facilitation within the spinal cord $(18,19)$, resulting from increased transmitter release, activation of cation channels, and blockade of glycine receptors (20). Central production of $\mathrm{PGE}_{2}$ also produces fever.

COX2 inhibitors reduce inflammatory pain hypersensitivity when given systemically (21-24) and intrathecally (25-27). What is uncertain, though, is the relative contribution of peripheral and central COX2 and of neural and non-neural prostanoids to inflammatory pain hypersensitivity. COX2 plays important roles in development (28), and mice deficient in COX2 display cardiovascular and renal defects conditioned by genetic background $(29,30)$. In the present studies, transgenic mice with Cre under the control of the Nestin promoter - which is expressed in all neural progenitors in the embryo (31) and will delete genes in neurons and glia but not microglia or endothelial cells $(32,33)$ - were mated with floxed $\operatorname{Cox} 2\left(\operatorname{Cox} 2^{f l / f l}\right)$ mice to generate mice with a conditional neural deletion of Cox2 in the CNS. We found that neural COX2 plays a pivotal role in the mechanical but not the thermal pain hypersensitivity evoked by peripheral inflammation but does not contribute to nociceptive pain, acute activity-dependent central sensitization, or fever.

\section{Results}

Generation of neural-specific Cox2-deficient mice. Nestin-Cre;Cox $2^{f l / f l}$ mice were generated by mating mice with a Cre transgene under control of the Nestin promoter with Cox $2^{f l f l}$ mice (Figure 1A) and genotyped for the presence of the Cre transgene and the loxP sites (Figure 1B). The Nes-Cre mouse line [B6.Cg-TgN(Nes-cre) $1 \mathrm{Kln} / \mathrm{J}]$ $(31,33)$ expresses Cre recombinase exclusively in neurons and glial 
A

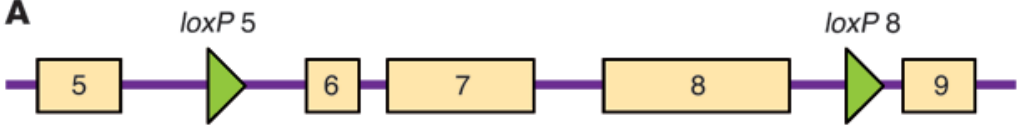

B

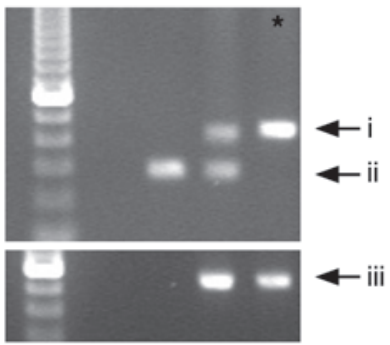

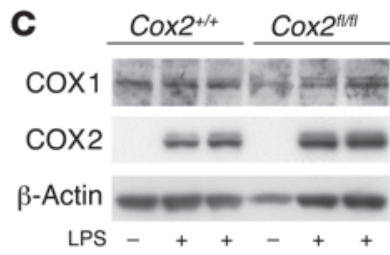
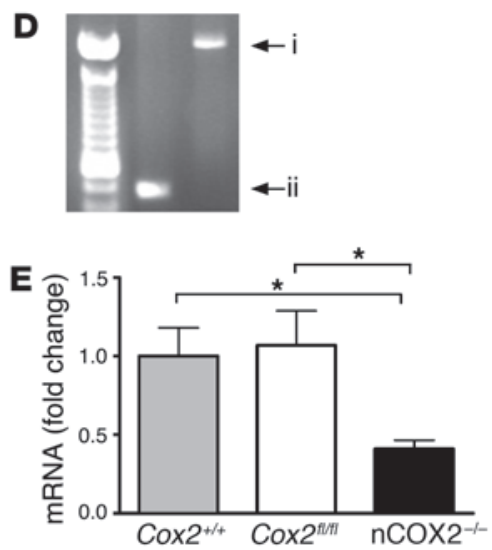

\section{Figure 1}

Generation of a neural-specific Cox2-deficient mouse. (A) loxP sites were inserted in introns 5 and 8 to enable deletion of exons 6-8. COX2 is functional and undisrupted after being flanked with loxP sites. $\beta$-Actin levels were used for loading control. (B) Genotyping of $n C O X 2^{-/-}$(Nes-

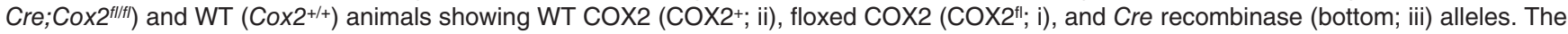

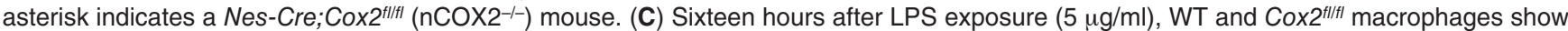
similar expression of both COX1 and COX2. (D) Detection of Nes-Cre-mediated deletion of Cox2 exons 6-8 by PCR, using primers targeted against introns 5 and 8 . The shorter fragment represents the recombined COX2 allele (COX2recomb; ii), whereas the longer one represents the nonrecombined allele (COX2Exon6-8; i). (E) Real-time quantitative PCR showing similar basal expression of COX2 in the spinal cord of WT C57BL/6 and Cox2 $2^{t / f t}$ controls, while nCOX2 $2^{-/-}$animals exhibit significantly lower Cox2 mRNA levels $\left({ }^{*} P<0.05, n=4-5\right.$, Student's $t$ test; mean \pm SEM).

cells (31-35). The 2 loxP sites in the Cox2 genomic locus do not affect its expression or induction, nor do they affect Cox 1 expression, as shown by COX2 induction by LPS and unchanged COX1 levels in cultured macrophages $(5 \mu \mathrm{g} / \mathrm{ml}, 16$ hours) (Figure 1C). Cre-mediated recombination of exons 6-8 of the Cox2 gene was detected in the spinal cord of the Nes-Cre; $\mathrm{Cox} 2^{f / f l}$ mice (Figure 1D), and these mice expressed significantly less constitutive COX2 in the spinal cord than Cox $2^{f / f l}$ control and WT animals $(P<0.05$, Student's $t$ test) (Figure 1E). We refer to Nes-Cre;Cox $2^{f l / f l}$ mice that lack COX2 in neurons and glial cells as nCOX2/- mice. No difference between WT and Cox $2^{f / f l}$ littermate controls was observed in all subsequent experiments.

COX2 expression in peripheral tissue of $n \mathrm{COX} 2^{-/-}$mice after peripheral inflammation. Intraplantar injection of CFA $(20 \mu \mathrm{l})$ into the hind paw produced an area of localized peripheral inflammation, with a significant increase in paw diameter (swelling) $(P<0.01$ compared with baseline, 1-way ANOVA with Dunnett's procedure) (Figure 2A). This increase was identical in control and $\mathrm{nCOX} 2^{-/-}$mice ( $\sim 30 \%$ increase in diameter), and a similar degree of inflammatory cell infiltrate and peripheral COX2 production was detected (Figure $2 \mathrm{~B})$. No Cox 2 mRNA was detected in the noninflamed hind paw of control and nCOX2 $2^{--}$mice, but Cox 2 mRNA ( 30- to 40-fold; $P<0.05$ and $P<0.01,1$-way ANOVA with Dunnett's procedure) and protein $(\sim 55$-fold, $P<0.001$, Student's $t$ test) levels increased after intraplantar CFA injection in control and $\mathrm{nCOX} 2^{-/-}$mice to an identical extent (Figure 2, C-E). These data suggest that the peripheral induction of COX2 is not altered in nCOX2 $2^{-/-}$mice.

COX2 expression in the spinal cord of $n \mathrm{COX} 2^{-/-}$mice after peripheral inflammation. Intraplantar injection of CFA significantly increased Cox 2 mRNA in the spinal cord at 6 and 12 hours in control mice ( $>5$-fold; $P<0.05$ and $P<0.01,1$-way ANOVA with Dunnett's procedure) (Figure 3A). However, Cox2 mRNA did not increase significantly in the spinal cord of nCOX2 $2^{-/-}$mice $(P>0.05)$ (Figure $3 \mathrm{~A})$. Immunohistochemistry and Western blot analysis confirmed the alteration in COX2 in the spinal cord of the $\mathrm{nCOX} 2^{-/-}$mice ( $<1.5$-fold) compared with control littermates ( $>6$-fold, $P<0.01$, Student's $t$ test) (Figure 3, B-D).

Basal nociception and acute hypersensitivity in $n \mathrm{COX} 2^{-1-}$ mice. To investigate the functional consequences of deletion of the Cox2 gene in neural tissue, we studied mechanical (von Frey threshold) and thermal (hot plate at $52^{\circ} \mathrm{C}$ ) pain sensitivity in $\mathrm{nCOX} 2^{-/-}$mice. No significant difference in basal mechanical or thermal sensitivity was detected between nCOX2-/- mice and their littermate controls (Figure 4A), indicating minimal contribution of COX2 expressed in neurons or glia to basal nociception. In order to test for acute chemical sensitivity, we injected $15 \mu \mathrm{l}$ of a $5 \%$ formalin solution intraplantarly (36). Intraplantar formalin evokes 2 phases of spontaneous pain-related behavior, an immediate short-lasting first phase due to activation of nociceptors and a second that reflects activity-dependent synaptic changes in the CNS (37-40). We found no change in formalin-induced pain sensitivity during the first phase and only a small, but significant, difference in the duration of pain behavior in the second phase (30-45 minutes) of the formalin test between $\mathrm{nCOX} 2^{-/-}$mice and their control littermates $(P<0.05$, Student's $t$ test), without changes in onset or peak (Figure $4 \mathrm{~B})$. These results imply only a limited contribution of constitutive neural COX2 to activity-dependent central sensitization.

Inflammatory pain hypersensitivity in $n \mathrm{COX} 2^{-/-}$mice. After induction of peripheral hind paw inflammation by CFA injection, mechanical threshold was reduced in control mice at 12 hours and remained decreased over the 10 days of examination $(P<0.01$ compared with baseline, 1-way ANOVA with Dunnett's procedure). However, no significant drop in mechanical threshold occurred in the $\mathrm{nCOX} 2^{-/-}$ mice over this entire time period $(P>0.05)$ (Figure 5A). In contrast, heat sensitivity decreased significantly and to an equivalent extent in nCOX2 $2^{-/-}$mice and littermate controls $(P<0.01$ and $P<0.001$ compared with baseline, 1-way ANOVA with Dunnett's procedure) (Figure 5B). Similar results were found for periarticular inflam- 

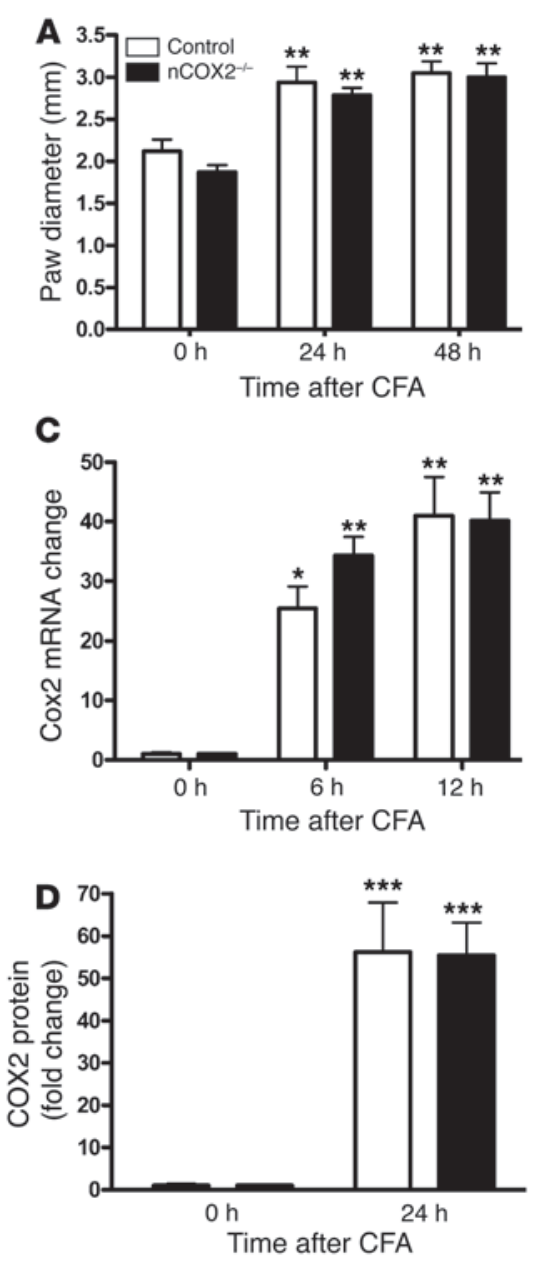

B
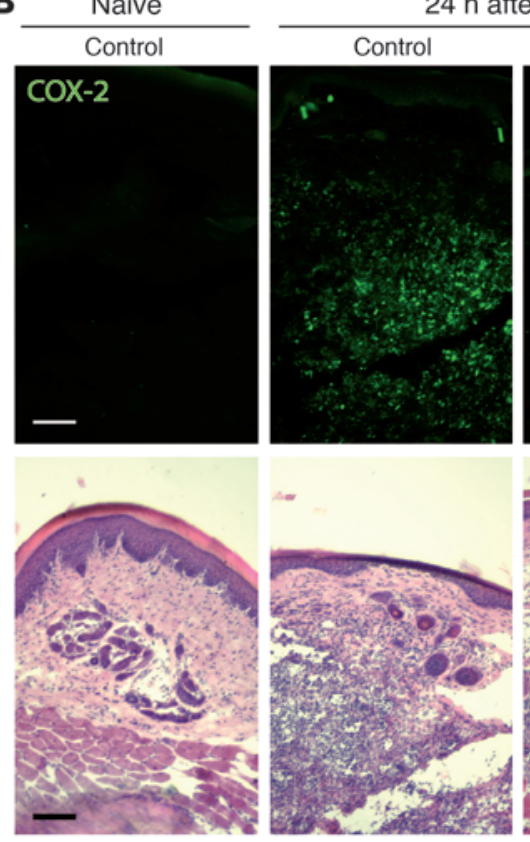

E

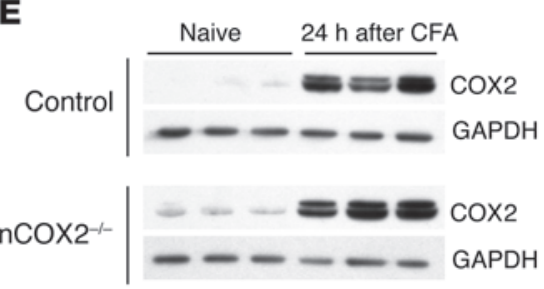

Figure 2

COX2 expression and development of peripheral inflammation in $\mathrm{nCOX} 2^{-1-}$ mice. (A) Paw swelling after intraplantar CFA injection. nCOX2 $2^{--}$and control mice show similar increases in paw diameter 24 and 48 hours after intraplantar CFA injection ${ }^{* *} P<0.01, n=6$, 1-way ANOVA with Dunnett's post test; mean \pm SEM). (B) Immunohistochemistry depicting, for both $\mathrm{nCOX} 2^{--}$and control mice, little or no COX2 expression in the naive paw but strong COX2 induction after CFA injection. H\&E staining reveals a comparable infiltration of inflammatory cells in both animals. Scale bars: $50 \mu \mathrm{m}$. (C) Quantitative real-time PCR results showing similar increases in Cox2 mRNA in the paw in $\mathrm{nCOX2}^{-/-}$and control mice $\left({ }^{\star} P<0.05,{ }^{* \star} P<0.01, n=5-6\right.$, 1-way ANOVA with Dunnett's post test; mean \pm SEM). (D and E) Western blots showing induction of COX2 in the paw in both animals in response to intraplantar CFA $\left({ }^{\star \star \star} P<0.001\right.$, $n=3$, Student's $t$ test; mean \pm SEM). GAPDH was used as internal control. mation. Periarticular CFA injection led to persistent swelling of the joint in control and nCOX2-/- mice, with a significant increase the tibiotarsal joint diameter at 14 days in both genotypes $(-50 \%$ increase in diameter; $P<0.001,1$-way ANOVA with Dunnett's procedure) (Figure 6A). However, the periarticular inflammation failed to induce the significant drop in hind paw mechanical threshold in the nCOX2 $2^{-/-}$mice over 21 days that occurred in littermate controls $(P<0.05$ and $P<0.01$ compared with baseline, 1-way ANOVA with Dunnett's procedure) (Figure 6B). Hind paw thermal hypersensitivity dropped similarly, though, in control and mutant mice $(P<0.05$ and $P<0.01$ compared with baseline, 1 -way ANOVA with Dunnett's procedure) (Figure 6C).

Loss of mechanical but not thermal hypersensitivity after peripheral inflammation in the conditional Cox 2 knockout prompted us to investigate whether thermal hypersensitivity after peripheral inflammation in the mutant mice is contributed to by non-neural COX2 activity, in either the periphery or non-neural cells in the CNS. To address this, we used systemic administration of the COX2 inhibitor SC-58236 (Pfizer Inc.) to block COX2 activity in both control and mutant mice and assessed inflammatory pain hypersensitivity. SC-58236 was administered systemically (i.p.) at a previously described dose of $30 \mathrm{mg} / \mathrm{kg}$ (41) to control and mutant mice after induction of peripheral hind paw inflammation with CFA. SC-58236 attenuated thermal hypersensitivity in both lines $(P<0.05$, Student's $t$ test) (Figure 5C). Systemic
SC-58236 also significantly reduced the CFA-induced mechanical hypersensitivity in WT mice (Figure 5D), confirming pharmacologically that this aspect of inflammatory pain hypersensitivity is COX2 dependent. At this dose, SC-58236 blocks $\mathrm{PGE}_{2}$ production in the spinal cord (41) and mechanical hyperalgesia in response to peripheral inflammation (42). SC-58236 had, as expected, no significant effect on mechanical threshold in the mutant mice (data not shown), since these animals have no mechanical hypersensitivity and COX2 inhibitors do not reduce basal mechanical threshold $(26,27,42)$. Our data indicate, therefore, that COX2 contributes to both mechanical and thermal pain hypersensitivity after peripheral inflammation, with neural COX2 largely regulating mechanical pain and COX2 at the site of the inflammation driving thermal hypersensitivity.

Fever in $n \mathrm{COX} 2^{-1-}$ mice. Fever is another feature of inflammation that results from central prostanoid action in the CNS (43). To examine whether neural COX2 contributes to fever, $\mathrm{nCOX} 2^{-/-}$and control mice were implanted with telemetric thermal sensors and injected with saline or $1 \mathrm{mg} / \mathrm{kg}$ LPS i.p. (Figure 6D) (44). All animals showed an initial stress fever due to handling during the injection procedure, but an elevation of body temperature between 90 and 180 minutes after injection was observed only in the LPS and not the saline-injected mice. The mean temperature difference between LPS and saline injection in the $\mathrm{nCOX} 2^{-/-}$mice $\left(0.8 \pm 0.1^{\circ} \mathrm{C}\right)$ was statistically indistinguishable from that in littermate controls. 


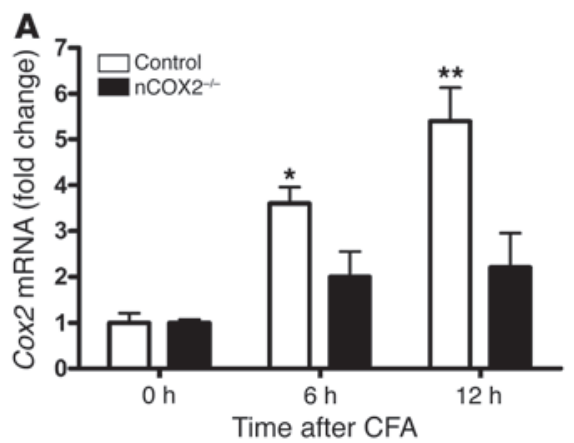

B
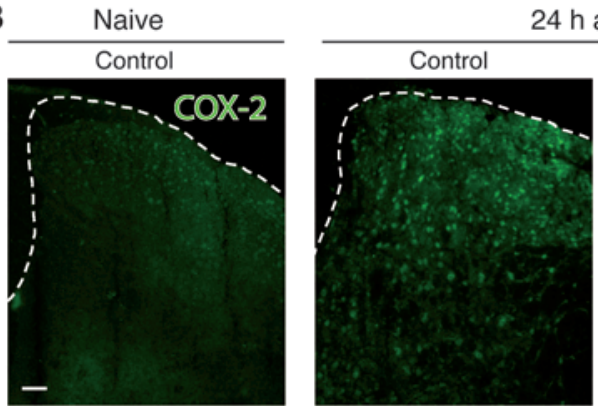

$4 \mathrm{~h}$ after CFA
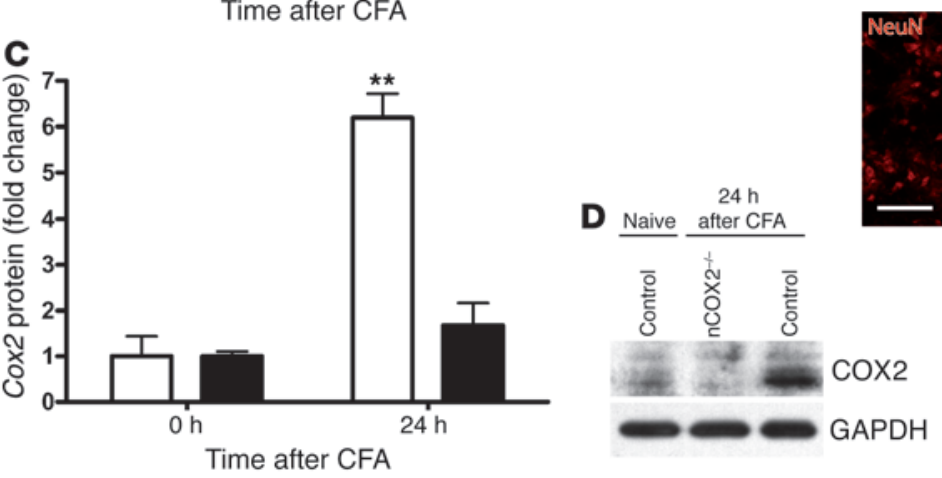

Figure 3

COX2 expression in the spinal cord of $\mathrm{nCOX2}^{-/-}$mice after peripheral inflammation. (A) After peripheral inflammation, spinal Cox2 mRNA levels are significantly increased in control animals $\left({ }^{\star} P<0.05,{ }^{* \star} P<0.01, n=4-5,1\right.$-way ANOVA with Dunnett's procedure). In contrast, a smaller but nonsignificant increase in spinal Cox2 mRNA expression is detected in nCOX2 $2^{-/}$mice $(P>0.05, n=4-5 ;$ mean \pm SEM). (B) Immunohistochemical study of COX2 expression in the dorsal horn of L4-L5 from control and nCOX2 ${ }^{-/}$mice. After peripheral inflammation (24 hours after CFA), COX2 expression is induced in the ipsilateral dorsal horn (dotted line) of control but not $\mathrm{nCOX} 2^{-/-}$mice. NeuN is used as a neuronal marker in the bottom row. Scale bars: $50 \mu \mathrm{m}$. (C and D) Western blots show induction of COX2 in the spinal cord of control animals after CFA injection ( ${ }^{\star *} P<0.01, n=3$, Student's $t$ test), whereas little or no COX2 protein is found in nCOX2 ${ }^{-1-}$ mice. GAPDH is used as internal control (mean \pm SEM).

\section{Discussion}

COX inhibitors, when delivered intrathecally, have an analgesic action on acute nociceptive and inflammatory pain (11, 25, 45-47). However, the extent to which this is mediated by inhibition of constitutively expressed COX1 or COX2 is disputed, as is whether COX2 induced in microglia or endothelial cells contributes (36, $45,48-50)$. We found no change in mechanical, thermal, or acute chemical (formalin phase 1) pain sensitivity in the neural COX2-null mice relative to littermate control mice, indicating minimal contribution of COX2 expressed in neurons or glia to basal nociception. Similarly, the involvement of COX1 and COX2 in acute ( $<1$ hour) activity-dependent central sensitization in the spinal cord is controversial. Formalin evokes an immediate short-lasting first phase due to the direct activation of TRPA1-expressing nociceptors (51) and a slower-onset, longer-lasting phase 2 that reflects a combination of ongoing sensory input and central sensitization in the spinal cord (37-40). Several studies show that constitutive COX1 expression in the spinal cord is required for development of the second phase of the formalin test (36), while others point to a role for $\operatorname{COX} 2(26,49$, $50,52,53)$ or an involvement of both (48). Only a small, but significant, difference in the duration of formalin-mediated pain behavior in the second phase between $\mathrm{nCOX} 2^{-/-}$mice and their control littermates was observed, with no change in onset or peak of sensitivity. Our data point therefore to a limited contribution of constitutive neural COX2 to activity-dependent central sensitization. Mice lacking the $\mathrm{EP}_{2}$ receptor, which mediates $\mathrm{PGE}_{2}$ pain-producing actions in the spinal cord, also show a reduction in pain indicators during the second phase of the formalin test (54).

Peripheral inflammation results, after several hours, in the induction of COX2 locally in immune cells at the site of the inflammation and in neurons in the dorsal horn (20). Our genetic approach has enabled us to dissect out the relative contribution of neural (neuronal and glial) COX2 to peripheral inflammatory pain hypersensitivity. The Nes-Cre driver, because it is expressed in all neural progenitor cells during embryogenesis, will delete Cox2 in neurons, astrocytes, and oligodendrocytes of the CNS (31) but will leave that in immune, microglial, and endothelial cells intact. Further studies using neuron- or glial cell-specific Cre drivers will be needed to define exactly which cell type is responsible for the change in phenotype. Similarly, deletion restricted to the spinal cord and different regions of the brain will be required to determine the precise anatomical locus of the effect. While peripheral inflammation developed normally in the $\mathrm{nCOX} 2^{-/}$mice, with high levels of local COX2 induced, absence of neural COX2 resulted in a loss of mechanical hypersensitivity in both models: soft tissue and periarticular inflammation. Thermal hypersensitivity was fully maintained in the $\mathrm{nCOX} 2^{-/}$mice after peripheral inflammation, but it was decreased by systemic administration of a COX2 inhibitor, SC-58236. This inhibitor reduced mechanical and thermal hypersensitivity in inflamed WT mice. Thus, neural COX2 seems to contribute to the mechanical component of inflammatory pain, whereas thermal sensitivity appears to rely on peripheral COX2 


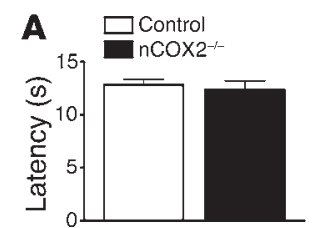

Hot plate $52^{\circ} \mathrm{C}$

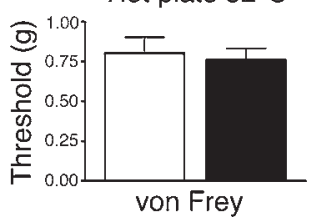

B

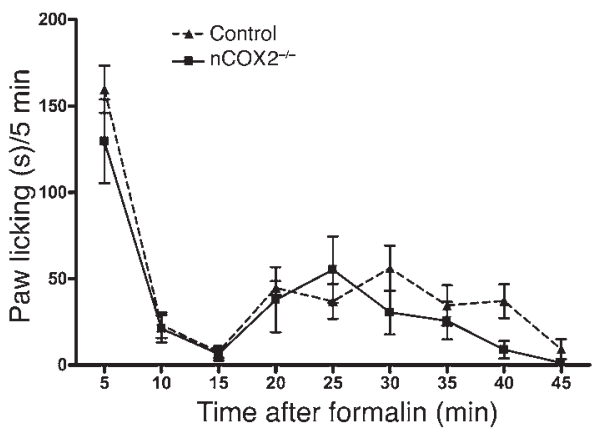

C

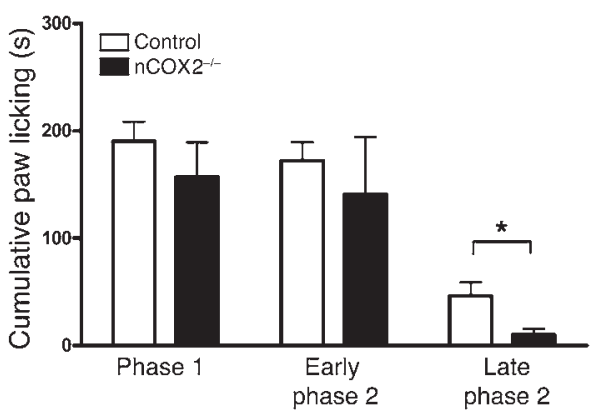

Figure 4

Basal and acute pain hypersensitivity in $\mathrm{nCOX} 2^{-/-}$mice. (A) No significant difference in basal mechanical or thermal sensitivity was detected between $\mathrm{nCOX}^{-1-}$ mice and littermate controls $(n=11-12$; mean \pm SEM). (B) Formalin test: Cumulative paw licking in 5-minute intervals after intraplantar formalin injection. nCOX2--- and control mice both show the typical biphasic response $(n=6$; mean \pm SEM). (C) Formalin test: nCOX $2^{-/-}$and control mice show a similar response in phase 1 (5-15 minutes) and early phase 2 (15-30 minutes) of the formalin reaction, whereas a slightly earlier recovery is apparent in late phase 2 (30-45 minutes) in the mutants ( ${ }^{\star} P<0.05$, Student's $t$ test, $n=6$; mean \pm SEM).

induction. Further studies are required to elucidate which cell types in the periphery drive the thermal hypersensitivity as well as prostanoid-dependent changes in inflammation. Because COX2 is not induced in the dorsal root ganglia after peripheral inflammation (55), it is very likely that it is COX2 induction in the CNS that generates inflammatory mechanical hypersensitivity (56).

Mice lacking the $\mathrm{EP}_{2}$ receptor also fail to develop mechanical hypersensitivity in the zymosan model of peripheral hind paw inflammation, as well as in response to intrathecally delivered
$\mathrm{PGE}_{2}$. These animals, however, exhibited some reduction in heat hyperalgesia after peripheral inflammation (57). One potential explanation for the diminished heat hyperalgesia in $\mathrm{EP}_{2}$ receptor- but not neural Cox2-deficient mice is the possible involvement of the receptor in $\mathrm{PGE}_{2}$-mediated peripheral sensitization acting on dorsal root ganglia neurons or immune cells, both of which express the receptor $(58,59)$. A potential role for COX1 as a contributor to thermal pain hypersensitivity in the CFA model in $\mathrm{nCOX} 2^{-/-}$mice cannot be ruled out. However, based on many
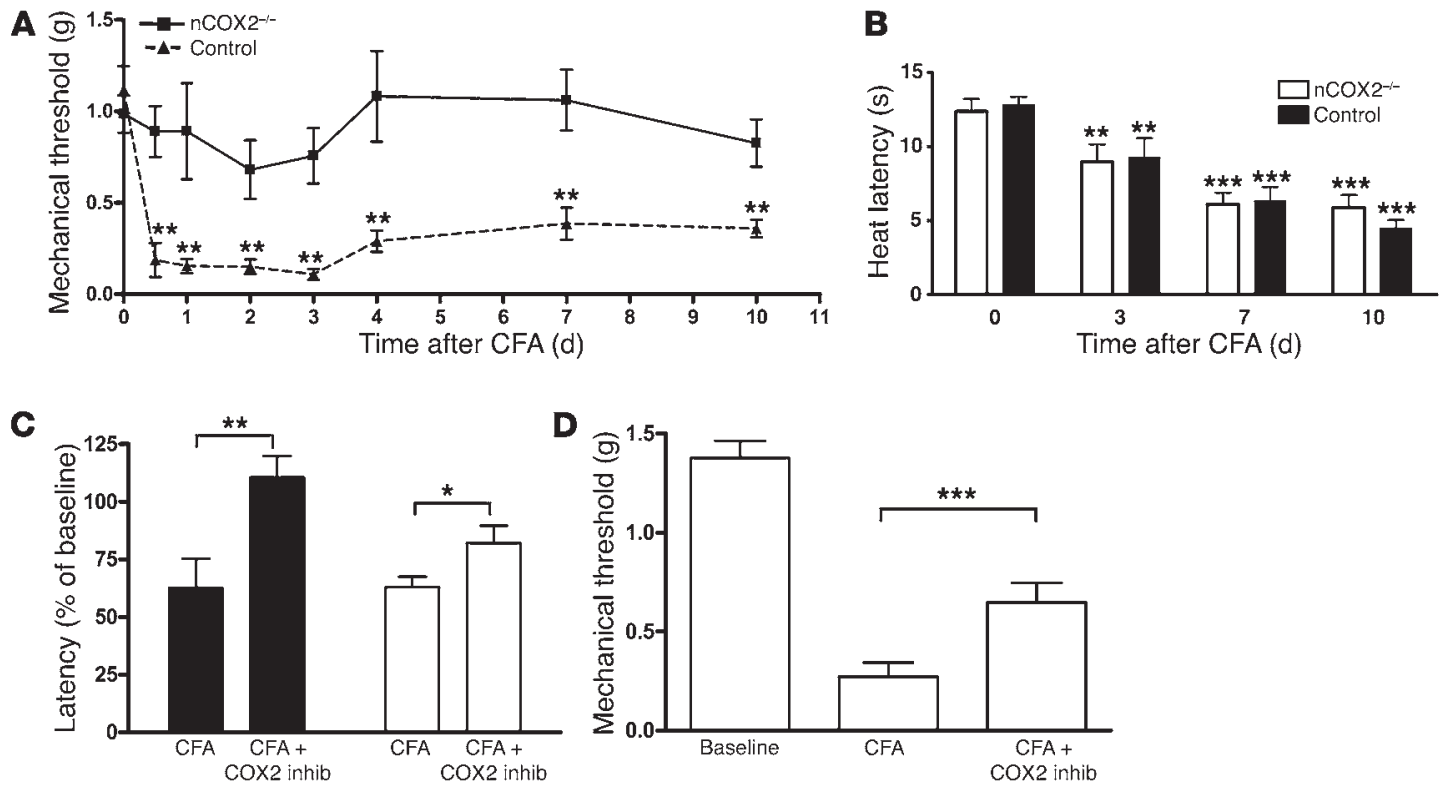

\section{Figure 5}

Mechanical and heat hypersensitivity in $\mathrm{nCOX} 2^{-1-}$ mice after peripheral inflammation and after administration of the selective COX2 inhibitor SC-58236. (A) After hind paw inflammation, mechanical threshold is significantly reduced in littermate control mice and remains decreased after 10 days. However, no significant drop in mechanical threshold is observed in nCOX2-- mice $\left({ }^{* \star} P<0.01, n=9-10\right.$; mean \pm SEM). (B) Thermal sensitivity threshold decreased in both nCOX $2^{-1-}$ and control littermates after paw inflammation $\left({ }^{* *} P<0.01,{ }^{* * *} P<0.001,1\right.$-way ANOVA with Dunnett's procedure, $n=9-10$; mean \pm SEM). (C) After i.p. administration of the COX2-selective inhibitor SC-58236 three days after CFAinduced inflammation (CFA + COX2 inhib), both littermate controls and $\mathrm{nCOX} 2^{-1-}$ animals exhibited increased heat thresholds $\left({ }^{\star} P<0.05\right.$ and ${ }^{\star \star} P<0.01$, Student's $t$ test, $n=6$; mean \pm SEM). (D) SC-58236 i.p. administration 3 days after CFA-induced inflammation significantly increases mechanical threshold in control animals $\left({ }^{* *} P<0.001\right.$, Student's $t$ test, $n=6$; mean \pm SEM). 

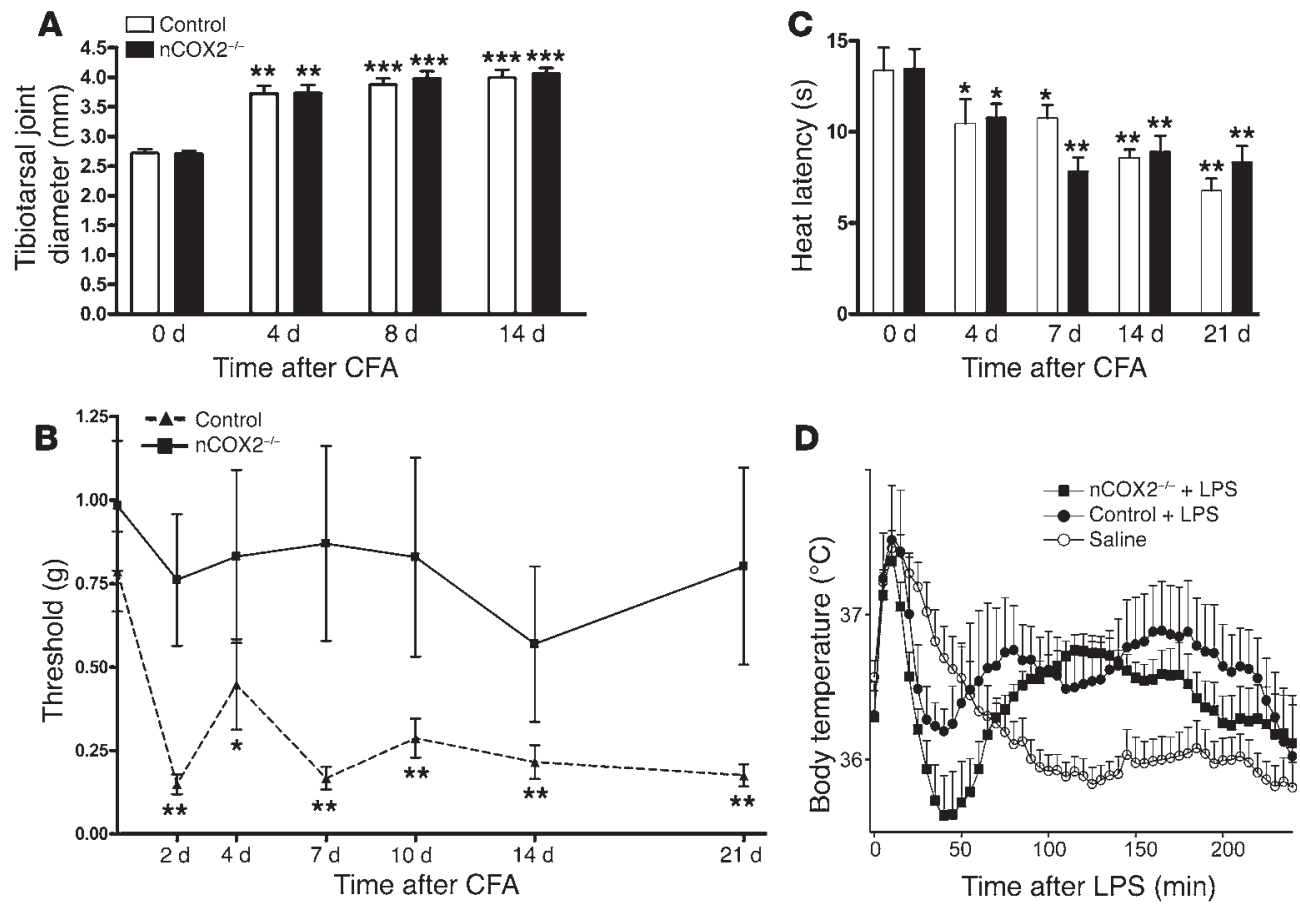

Figure 6

Mechanical and heat hypersensitivity in nCOX2-- mice after induction of periarticular inflammation and fever response to LPS. (A) Swelling of the tibiotarsal joint after periarticular injection of CFA in nCOX2 $2^{--}$and control mice $\left({ }^{* \star} P<0.01\right.$ and ${ }^{* \star *} P<0.001,1$-way ANOVA with Dunnett's procedure, $n=12$; mean \pm SEM). (B) The joint inflammation induced a significant drop in hind paw mechanical threshold in the littermate control over 21 days but failed to do so in the nCOX2 ${ }^{-1-}$ mice $\left({ }^{*} P<0.05\right.$, ${ }^{* *} P<0.01,1$-way ANOVA with Dunnett's procedure, $n=12 ;$ mean \pm SEM). (C) Thermal hypersensitivity in the hind paw was present in both littermate control and nCOX2 $2^{--}$mice $\left({ }^{*} P<0.05\right.$ and ${ }^{* *} P<0.01,1$-way ANOVA with Dunnett's procedure, $n=11-12$; mean \pm SEM). (D) Effect of i.p. LPS on body temperature in nCOX2 ${ }^{-1-}$ mice. The mice were injected with LPS $(1 \mathrm{mg} / \mathrm{kg})$ or $0.9 \%$ saline at time 0 . Between 90 and 180 minutes, fever in $\mathrm{nCOX} 2^{-1-}$ mice did not differ from that in littermate control mice $(P>0.05, n=8$; mean \pm SEM) .

pharmacological and genetic studies, the contribution of COX2 to inflammatory pain appears to be predominant (10).

Since patients with arthritis and many other inflammatory conditions typically present with complaints of mechanical (joint movement, tenderness to touch) rather than thermal pain, centrally acting nonselective or selective COX2 inhibitors may be more effective analgesics in these conditions than inhibitors that do not cross the blood-brain barrier $(36,60,61)$. This contrasts with the situation in individuals with injuries such as sunburn and other dermatological conditions where heat pain threshold drops substantially, for whom peripherally acting COX2 inhibitors may be more effective $(62,63)$.

Because LPS-induced fever is not reduced in $\mathrm{nCOX} 2^{-/-}$mice, our data suggest that neural COX2 is not required for fever. Our results are in agreement with several reports showing that, in response to peripheral and systemic inflammation, brain endothelial cells begin to express COX2 with a time course parallel to that of the fever response curve $(64,65)$. Moreover, mice with total deletion of Cox2 but not Cox 1 fail to exhibit a fever response after LPS injection (66). COX2 expression in macrophages and endothelial cells associated with small penetrating venules along the surface of the brain contributes to the fever response by producing the prostanoids that act on specific neurons in the preoptic nucleus $(43,67,68)$.

In conclusion, our results indicate that COX2 expressed within neurons and glia of the CNS plays an essential role in the development of inflammatory mechanical pain hypersensitivity, while heat hyperalgesia appears to depend largely on non-neuronal COX2, most probably generated by immune and other cells at the site of the peripheral inflammation.

\section{Methods}

All experiments adhered to the guidelines of the Committee for Research and Ethical Issues of the International Association for the Study of Pain (IASP). The Subcommittee on Research Animal Care (SRAC) of Massachusetts General Hospital approved the experimental protocol.

Generation of conditional Cox2-deficient mice. Cox $2^{f / / f l}$ mice were generated by inserting $\operatorname{lox} P$ sites, using homologous recombination, in introns 5 and 8 to enable deletion of exons 6-8 (Figure 1A). The insertion of the 2 loxP sites did not affect normal COX2 expression and induction. NesCre transgenic mice were obtained from The Jackson Laboratory [B6.Cg$\operatorname{TgN}($ Nes-cre) $1 \mathrm{~K} \ln / \mathrm{J}]$. These mice express Cre recombinase under control of the rat Nestin (35) promoter and intron 2 enhancer $(31,33)$. Male Nes$\mathrm{Cre} ; \mathrm{Cox} 2^{f l /+}$ mice were mated with female Cox $2^{f l f l}$ mice (69) to obtain NesCre; $\operatorname{Cox}_{2}{ }^{f / f l}$ mutants, with deletion of Cox 2 exons 6-8. All animals were on a C57BL/ 6 background.

PCR. For genotyping, genomic DNA was extracted from tails and used for PCR with AccuPrime SuperMix II (Invitrogen) and the following primers: Nes-Cre, 5'-GCGATTATCTTCTATATCTTCA-3' and 5'-CAGGTAGTTATTCGGATCAT-3'; Cox $2^{f / / l}, 5^{\prime}$-TGAGGCAGAAAGAGGTCCAGCCTT-3' and $5^{\prime}$-ACCAATACTAGCTCAATAAGTGAC-3'; and for confirmation of Nes-Cre-mediated recombination, 5'-ACCAATACTAGCTCAATAAGTGAC-3' and 5'-TTTGCCACTGCTTGTACAGCAATT-3'. 
Induction of peripheral inflammation. Twenty microliters of CFA (SigmaAldrich) was injected under isoflurane anesthesia subcutaneously into the plantar surface of the hind paw for induction of paw inflammation. Seventy microliters of CFA was injected subcutaneously at 2 sites around the left tibiotarsal joint for induction of periarticular inflammation (70). Paw edema and joint diameter were measured using a Micrometer Caliper (Thermo Fisher Scientific Inc.).

Immunohistochemistry. Twenty-four hours after CFA injection, fresh paw and spinal cord tissue (L3-L5) were harvested, cryosectioned at $14 \mu \mathrm{m}$, and stored at $-80^{\circ} \mathrm{C}$. slides were fixed in $4 \%$ paraformaldehyde, washed in PBS, and blocked with blocking solution (1\% BSA in PBS, $0.1 \%$ Triton X-100). Sections were incubated overnight with anti-murine COX2 antibody (Cayman Chemical) at 1:400 (spinal cord) and 1:200 (paw). Double staining with NeuN was performed at 1:2,000 (mouse monoclonal antibody; Chemicon, Millipore). COX2 and NeuN were visualized with FITC-conjugated donkey anti-rabbit IgG (1:200) and Cy3-conjugated goat anti-mouse IgG (1:500; both Jackson ImmunoResearch Laboratories Inc.).

Real-time quantitative PCR. Paw and spinal cord (L3-L5) tissues were harvested and total RNA extracted using TRIzol (Invitrogen). Quantitative real-time PCR was performed after reverse transcription, using the PowerSYBR Green detection system with primer sets designed on Primer Express (Applied Biosystems). Specific PCR product amplification was confirmed using the dissociation protocol. Transcript regulation was determined using the relative standard curve method (Applied Biosystems). Relative loading was determined prior to reverse transcription with RNA spectrophotometry followed by gel electrophoresis and after reverse transcription by amplification of GAPDH.

Western blotting. Paw and spinal cord tissues were harvested 24 hours after CFA injection and processed in lysis buffer $(6 \mathrm{mg} / \mathrm{ml}$ Tris, $9 \mathrm{mg} / \mathrm{ml} \mathrm{NaCl}$, $0.37 \mathrm{mg} / \mathrm{ml} \mathrm{EDTA}, 10 \mu \mathrm{l} / \mathrm{ml}$ of $1 \mathrm{mM}$ DTT and PMSF and Protease Inhibitor Cocktail [Roche]). Tissue was homogenized and quantified by optical density $(490 \mathrm{~nm})$ using the BCA Protein Assay Kit (Pierce). Fifteen micrograms (paw) and $20 \mu \mathrm{g}$ (spinal cord) protein were run on a NuPAGE 4-12\% Bis-Tris Gel (Invitrogen) transferred to a Immuno-Blot PVDF Membrane (Bio-Rad), washed in PBS-Tween (PBS-T) (0.05\%), and blocked with 5\% fat-free milk powder in PBS-T for 1 hour at room temperature. The membrane was incubated with a mouse COX2 antibody (Cayman Chemical) at 1:200 (spinal cord) and 1:500 (paw) for 48 hours at $4^{\circ} \mathrm{C}$. Rabbit anti-mouse GAPDH antibody (1:3,000; Santa Cruz Biotechnology Inc.) was used as loading control. At least 3 samples were analyzed by densitometry and corrected for GAPDH values.

Behavioral testing. nCOX2-/- animals and control littermates (aged 9-16 weeks) were habituated in 2 separate sessions. On 3 separate days spread out over 1 week, baseline values were obtained for basal heat and mechanical nociception using the technique described below. All withdrawal latencies were measured manually. The observer was fully blinded to the experimental protocol for all tests.

Mechanical allodynia. Animals were placed on an elevated wire grid and the plantar hind paw stimulated using von Frey monofilaments (0.0174-57.5 g) (71). Withdrawal threshold was determined as the filament at which the animal withdrew its paw after at least 3 of 10 applications.

Thermal hyperalgesia. Animals were placed on a hot plate, which was set to $52^{\circ} \mathrm{C}$, and timing was started immediately. The time until nociceptive behavior (defined as lifting, shaking, or licking the injured paw) occurred was recorded manually for each animal and the animal immediately removed from the hot plate. The COX2 inhibitor SC-58236 (30 mg/kg; Pfizer Inc.) was injected i.p. with $100 \mu$ l vehicle (20\% DMSO) 2 hours prior to behavioral testing.

Formalin. Fifteen microliters of a 5\% formaldehyde solution (SigmaAldrich) was injected subcutaneously into the plantar surface on one side. The time spent licking the injected paw was recorded in 5-minute intervals up to 45 minutes after formalin injection.

Fever. The animals were implanted with i.p. telemetric thermal sensors and injected i.p. with saline or with $1 \mathrm{mg} / \mathrm{kg}$ LPS as described previously (44).

Statistics. All data are expressed as mean \pm SEM. Two-tailed Student's $t$ test or 1-way ANOVA with Dunnett's procedure was used where appropriate. $P$ values less than 0.05 were considered significant.

\section{Acknowledgments}

We thank Joachim Scholz for advice, Thomas Gärtner for work on figures, and the NIH for grants NS039518 (to C.J. Woolf) and HL62250 (to D. Wang and G.A. FitzGerald). G.A. FitzGerald is the McNeil Professor of Translational Medicine and Therapeutics.

Received for publication August 11, 2008, and accepted in revised form November 11, 2008.

Address correspondence to: Clifford Woolf, Department of Anesthesia and Critical Care, Massachusetts General Hospital, 149 13th Street, Charlestown, Massachusetts 02129, USA. Phone: (617) 724-3622; Fax: (617) 724-3632; E-mail: cwoolf@partners. org. Or to: Garret A. FitzGerald, 153 Johnson Pavilion, School of Medicine, University of Pennsylvania, Philadelphia, Pennsylvania 19104, USA. Phone: (215) 898-1185; Fax: (215) 573-9135; E-mail: garret@spirit.gcrc.upenn.edu.
1. Garavito, R.M., and DeWitt, D.L. 1999. The cyclooxygenase isoforms: structural insights into the conversion of arachidonic acid to prostaglandins. Biochim. Biophys. Acta. 1441:278-287.

2. Smith, W.L., DeWitt, D.L., and Garavito, R.M. 2000. Cyclooxygenases: structural, cellular, and molecular biology. Annu. Rev. Biochem. 69:145-182.

3. Minami, T., et al. 2001. Characterization of EP receptor subtypes responsible for prostaglandin E2induced pain responses by use of EP1 and EP3 receptor knockout mice. Br. J. Pharmacol. 133:438-444.

4. Narumiya, S., Sugimoto, Y., and Ushikubi, F. 1999. Prostanoid receptors: structures, properties, and functions. Physiol. Rev. 79:1193-1226.

5. Sugimoto, Y., Narumiya, S., and Ichikawa, A. 2000. Distribution and function of prostanoid receptors: studies from knockout mice. Prog. Lipid Res. 39:289-314.

6. Breyer, R.M., Bagdassarian, C.K., Myers, S.A., and Breyer, M.D. 2001. Prostanoid receptors: subtypes and signaling. Annu. Rev. Pharmacol. Toxicol. 41:661-690.
7. Dantzer, R., et al. 1998. Molecular basis of sickness behavior. Ann. N. Y. Acad. Sci. 856:132-138.

8. McAdam, B.F., et al. 2000. Effect of regulated expression of human cyclooxygenase isoforms on eicosanoid and isoeicosanoid production in inflammation. J. Clin. Invest. 105:1473-1482.

9. FitzGerald, G.A., and Patrono, C. 2001. The coxibs, selective inhibitors of cyclooxygenase-2. N. Engl. J. Med. 345:433-442.

10. Burian, M., and Geisslinger, G. 2005. COX-dependent mechanisms involved in the antinociceptive action of NSAIDs at central and peripheral sites. Pharmacol. Ther. 107:139-154.

11. Samad, T.A., et al. 2001. Interleukin-1beta-mediated induction of Cox- 2 in the CNS contributes to inflammatory pain hypersensitivity. Nature. 410:471-475.

12. Laflamme, N., Lacroix, S., and Rivest, S. 1999. An essential role of interleukin-1beta in mediating NF-kappaB activity and COX-2 transcription in cells of the blood-brain barrier in response to a systemic and localized inflammation but not during endotoxemia. J. Neurosci. 19:10923-10930.
13. Moriyama, T., et al. 2005. Sensitization of TRPV1 by EP1 and IP reveals peripheral nociceptive mechanism of prostaglandins. Mol. Pain. 1:3.

14. Fischer, M.J., and Reeh, P.W. 2007. Sensitization to heat through G-protein-coupled receptor pathways in the isolated sciatic mouse nerve. Eur. J. Neurosci. 25:3570-3575.

15. Jarvis, M.F., et al. 2007. A-803467, a potent and selective Nav1.8 sodium channel blocker, attenuates neuropathic and inflammatory pain in the rat. Proc. Natl. Acad. Sci. U. S. A. 104:8520-8525.

16. England, S., Bevan, S., and Docherty, R.J. 1996. PGE2 modulates the tetrodotoxin-resistant sodium current in neonatal rat dorsal root ganglion neurones via the cyclic AMP-protein kinase A cascade. J. Physiol. 495:429-440.

17. Gold, M.S. 1999. Tetrodotoxin-resistant Na+ currents and inflammatory hyperalgesia. Proc. Natl. Acad. Sci. U. S. A. 96:7645-7649.

18. Dirig, D.M., and Yaksh, T.L. 1999. Spinal synthesis and release of prostanoids after peripheral injury and inflammation. Adv. Exp. Med. Biol. 469:401-408. 
19. Vanegas, H., and Schaible, H.G. 2001. Prostaglandins and cyclooxygenases [correction of cycloxygenases] in the spinal cord. Prog. Neurobiol. 64:327-363.

20. Samad, T.A., Sapirstein, A., and Woolf, C.J. 2002. Prostanoids and pain: unraveling mechanisms and revealing therapeutic targets. Trends Mol. Med. 8:390-396.

21. Chan, C.C., et al. 1999. Rofecoxib [Vioxx, MK-0966; 4-(4'-methylsulfonylphenyl)-3-phenyl-2-(5H)-furanone]: a potent and orally active cyclooxygenase- 2 inhibitor. Pharmacological and biochemical profiles. J. Pharmacol. Exp. Ther. 290:551-560.

22. Riendeau, D., et al. 1997. Biochemical and pharmacological profile of a tetrasubstituted furanone as a highly selective COX-2 inhibitor. Br. J. Pharmacol. 121:105-117.

23. Chan, C.C., et al. 1995. Pharmacology of a selective cyclooxygenase- 2 inhibitor, L-745,337: a novel nonsteroidal anti-inflammatory agent with an ulcerogenic sparing effect in rat and nonhuman primate stomach. J. Pharmacol. Exp. Ther. 274:1531-1537.

24. Seibert, K., et al. 1994. Pharmacological and biochemical demonstration of the role of cyclooxygenase 2 in inflammation and pain. Proc. Natl. Acad. Sci. U. S. A. 91:12013-12017.

25. Dirig, D.M., Isakson, P.C., and Yaksh, T.L. 1998. Effect of COX-1 and COX-2 inhibition on induction and maintenance of carrageenan-evoked thermal hyperalgesia in rats. J. Pharmacol. Exp. Ther. 285:1031-1038.

26. Yaksh, T.L., et al. 2001. The acute antihyperalgesic action of nonsteroidal, anti-inflammatory drugs and release of spinal prostaglandin E2 is mediated by the inhibition of constitutive spinal cyclooxygenase-2 (COX-2) but not COX-1. J. Neurosci. 21:5847-5853.

27. Matsunaga, A., et al. 2007. Intrathecally administered COX-2 but not COX-1 or COX-3 inhibitors attenuate streptozotocin-induced mechanical hyperalgesia in rats. Eur. J. Pharmacol. 554:12-17.

28. Lim, H., et al. 1997. Multiple female reproductive failures in cyclooxygenase 2-deficient mice. Cell. 91:197-208.

29. Loftin, C.D., et al. 2001. Failure of ductus arteriosus closure and remodeling in neonatal mice deficient in cyclooxygenase-1 and cyclooxygenase-2. Proc. Natl. Acad. Sci. U. S. A. 98:1059-1064.

30. Morham, S.G., et al. 1995. Prostaglandin synthase 2 gene disruption causes severe renal pathology in the mouse. Cell. 83:473-482.

31. Zimmerman, L., et al. 1994. Independent regulatory elements in the nestin gene direct transgene expression to neural stem cells or muscle precursors. Neuron. 12:11-24.

32. Graus-Porta, D., et al. 2001. Beta1-class integrins regulate the development of laminae and folia in the cerebral and cerebellar cortex. Neuron. 31:367-379.

33. Tronche, F., et al. 1999. Disruption of the glucocorticoid receptor gene in the nervous system results in reduced anxiety. Nat. Genet. 23:99-103.

34. Bruning, J.C., et al. 2000. Role of brain insulin receptor in control of body weight and reproduction. Science. 289:2122-2125.

35. Gao, Q., et al. 2004. Disruption of neural signal transducer and activator of transcription 3 causes obesity, diabetes, infertility, and thermal dysregulation. Proc. Natl. Acad. Sci. U. S. A. 101:4661-4666.

36. Tegeder, I., Niederberger, E., Vetter, G., Brautigam, L., and Geisslinger, G. 2001. Effects of selective COX-1 and -2 inhibition on formalin-evoked nociceptive behaviour and prostaglandin $\mathrm{E}(2)$ release in the spinal cord. J. Neurochem. 79:777-786.

37. Coderre, T.J., and Melzack, R. 1992. The contribu- tion of excitatory amino acids to central sensitization and persistent nociception after formalininduced tissue injury. J. Neurosci. 12:3665-3670.

38. Coderre, T.J., Vaccarino, A.L., and Melzack, R. 1990. Central nervous system plasticity in the tonic pain response to subcutaneous formalin injection. Brain Res. 535:155-158.

39. McCall, W.D., Tanner, K.D., and Levine, J.D. 1996. Formalin induces biphasic activity in C-fibers in the rat. Neurosci. Lett. 208:45-48.

40. Puig, S., and Sorkin, L.S. 1996. Formalin-evoked activity in identified primary afferent fibers: systemic lidocaine suppresses phase-2 activity. Pain. 64:345-355.

41. Koetzner, L., Hua, X.Y., Lai, J., Porreca, F., and Yaksh, T. 2004. Nonopioid actions of intrathecal dynorphin evoke spinal excitatory amino acid and prostaglandin E2 release mediated by cyclooxygenase-1 and -2. J. Neurosci. 24:1451-1458.

42. Francischi, J.N., et al. 2002. Selective inhibitors of cyclo-oxygenase-2 (COX-2) induce hypoalgesia in a rat paw model of inflammation. Br. J. Pharmacol. 137:837-844.

43. Rudaya, A.Y., Steiner, A.A., Robbins, J.R., Dragic, A.S., and Romanovsky, A.A. 2005. Thermoregulatory responses to lipopolysaccharide in the mouse: dependence on the dose and ambient temperature. Am. J. Physiol. Regul. Integr. Comp. Physiol. 289:R1244-R1252.

44. Lazarus, M., et al. 2007. EP3 prostaglandin receptors in the median preoptic nucleus are critical for fever responses. Nat. Neurosci. 10:1131-1133.

45. Dirig, D.M., Konin, G.P., Isakson, P.C., and Yaksh, T.L. 1997. Effect of spinal cyclooxygenase inhibitors in rat using the formalin test and in vitro prostaglandin E2 release. Eur. J. Pharmacol. 331:155-160.

46. Malmberg, A.B., and Yaksh, T.L. 1992. Hyperalgesia mediated by spinal glutamate or substance $P$ receptor blocked by spinal cyclooxygenase inhibition. Science. 257:1276-1279.

47. Malmberg, A.B., and Yaksh, T.L. 1995. Cyclooxygenase inhibition and the spinal release of prostaglandin E2 and amino acids evoked by paw formalin injection: a microdialysis study in unanesthetized rats. J. Neurosci. 15:2768-2776.

48. Euchenhofer, C., Maihofner, C., Brune, K., Tegeder, I., and Geisslinger, G. 1998. Differential effect of selective cyclooxygenase-2 (COX-2) inhibitor NS 398 and diclofenac on formalin-induced nociception in the rat. Neurosci. Lett. 248:25-28.

49. Veiga, A.P., et al. 2004. Prevention by celecoxib of secondary hyperalgesia induced by formalin in rats. Life Sci. 75:2807-2817.

50. Yamamoto, T., and Nozaki-Taguchi, N. 2002. The role of cyclooxygenase- 1 and -2 in the rat formalin test. Anesth. Analg. 94:962-967.

51. McNamara, C.R., et al. 2007. TRPA1 mediates formalin-induced pain. Proc. Natl. Acad. Sci. U. S. A. 104:13525-13530.

52. Ghilardi, J.R., Svensson, C.I., Rogers, S.D., Yaksh, T.L., and Mantyh, P.W. 2004. Constitutive spinal cyclooxygenase- 2 participates in the initiation of tissue injury-induced hyperalgesia. J. Neurosci. 24:2727-2732.

53. Ramos, K.M., Jiang, Y., Svensson, C.I., and Calcutt, N.A. 2007. Pathogenesis of spinally mediated hyperalgesia in diabetes. Diabetes. 56:1569-1576.

54. Hosl, K., et al. 2006. Spinal prostaglandin E receptors of the EP2 subtype and the glycine receptor alpha3 subunit, which mediate central inflammatory hyperalgesia, do not contribute to pain after peripheral nerve injury or formalin injection. Pain. 126:46-53.
55. Chopra, B., et al. 2000. Cyclooxygenase- 1 is a marker for a subpopulation of putative nociceptive neurons in rat dorsal root ganglia. Eur. J. Neurosci. 12:911-920.

56. Lee, K.M., et al. 2004. Spinal NF-kB activation induces COX-2 upregulation and contributes to inflammatory pain hypersensitivity. Eur. J. Neurosci. 19:3375-3381.

57. Reinold, H., et al. 2005. Spinal inflammatory hyperalgesia is mediated by prostaglandin $E$ receptors of the EP2 subtype. J. Clin. Invest. 115:673-679.

58. Jenkins, D.W., Feniuk, W., and Humphrey, P.P. 2001. Characterization of the prostanoid receptor types involved in mediating calcitonin gene-related peptide release from cultured rat trigeminal neurones. Br. J. Pharmacol. 134:1296-1302.

59. Treffkorn, L., Scheibe, R., Maruyama, T., and Dieter, P. 2004. PGE2 exerts its effect on the LPSinduced release of TNF-alpha, ET-1, IL-1alpha, IL-6 and IL-10 via the EP2 and EP4 receptor in rat liver macrophages. Prostaglandins Other Lipid Mediat. 74:113-123.

60. Dembo, G., Park, S.B., and Kharasch, E.D. 2005. Central nervous system concentrations of cyclooxygenase-2 inhibitors in humans. Anesthesiology. 102:409-415.

61. Mehta, V., Johnston, A., Cheung, R., Bello, A., and Langford, R.M. 2008. Intravenous parecoxib rapidly leads to COX-2 inhibitory concentration of valdecoxib in the central nervous system. Clin. Pharmacol. Ther. 83:430-435.

62. Gustorff, B., Anzenhofer, S., Sycha, T., Lehr, S., and Kress, H.G. 2004. The sunburn pain model: the stability of primary and secondary hyperalgesia over 10 hours in a crossover setting. Anesth. Analg. 98:173-177.

63. Sycha, T., et al. 2005. Rofecoxib attenuates both primary and secondary inflammatory hyperalgesia: a randomized, double blinded, placebo controlled crossover trial in the UV-B pain model. Pain. 113:316-322.

64. Matsumura, K., et al. 1998. Brain endothelial cells express cyclooxygenase- 2 during lipopolysaccharide-induced fever: light and electron microscopic immunocytochemical studies. J. Neurosci. 18:6279-6289.

65. Ek, M., et al. 2001. Inflammatory response: pathway across the blood-brain barrier. Nature. 410:430-431.

66. Li, S., et al. 1999. The febrile response to lipopolysaccharide is blocked in cyclooxygenase-2(-/-), but not in cyclooxygenase-1(-/-) mice. Brain Res. 825:86-94.

67. Elmquist, J.K., et al. 1997. Intravenous lipopolysaccharide induces cyclooxygenase 2-like immunoreactivity in rat brain perivascular microglia and meningeal macrophages. J. Comp. Neurol. 381:119-129.

68. Schiltz, J.C., and Sawchenko, P.E. 2002. Distinct brain vascular cell types manifest inducible cyclooxygenase expression as a function of the strength and nature of immune insults. J. Neurosci. 22:5606-5618.

69. Trumpp, A., Depew, M.J., Rubenstein, J.L., Bishop, J.M., and Martin, G.R. 1999. Cre-mediated gene inactivation demonstrates that FGF8 is required for cell survival and patterning of the first branchial arch. Genes Dev 13:3136-3148.

70. Chillingworth, N.L., and Donaldson, L.F. 2003. Characterisation of a Freund's complete adjuvantinduced model of chronic arthritis in mice. J. Neurosci. Methods. 128:45-52.

71. Decosterd, I., and Woolf, C.J. 2000. Spared nerve injury: an animal model of persistent peripheral neuropathic pain. Pain. 87:149-158. 